\title{
EFEITOS SOCIOECONÔMICOS DO CULTIVO DE EUCALIPTO NO DESENVOLVIMENTO DE MUNICÍPIOS PRODUTORES DA BAHIA, BRASIL
}

\author{
Mônica de Moura Pires ${ }^{1}$ \\ Paulo César Bahia de Aguiar² \\ Érika Giulia Fragas Santana ${ }^{3}$
}

Resumo: Este artigo tem como principal objetivo analisar os efeitos socioeconômicos do cultivo de eucalipto no desenvolvimento de municípios produtores, no estado da Bahia, Brasil. Como metodologia, procedeu-se a uma análise panorâmica recente da produção de madeira em tora para produção de papel e celulose nos principais estados brasileiros produtores; fez-se caracterização da silvicultura no estado da Bahia; identificaram-se as possíveis influências da atividade em estudo sobre a economia dos municípios estudados, por meio de dados econômicos e da estrutura agrária; analisaram-se as possíveis transformações sociais nos municípios estudados, por meio de dados socioeconômicos. De acordo com os resultados, nota-se que a expansão da atividade em questão gerou maior concentração de terras em função do aumento no número de grandes propriedades rurais, migração da população rural para espaços urbanos, e que não foi capaz de propiciar benefícios para a população desses locais, sob o ponto de vista dos indicadores socioeconômicos analisados.

Palavras-chave: Silvicultura. Municípios produtores. Transformação socioeconômica. Desenvolvimento regional.

\section{SOCIOECONOMIC EFFECTS OF EUCALYPTUS CULTURE ON THE DEVELOPMENT OF PRODUCING MUNICIPALS OF BAHIA, BRAZIL}

Abstract: This article aims to analyze the socioeconomic effects of eucalyptus cultivation on the development of producing municipalities in the state of Bahia, Brazil. As a methodology, it was made a recent panoramic analysis of the production of logs for pulp and paper production in the main Brazilian producing states; characterization of forestry in the state of Bahia; Identification of possible influences of the productive activity on the economy of the studied municipalities, through economic data and the agrarian structure analysis; Possible social transformations in the municipalities studied were analyzed through socioeconomic data. According to the results, it is noted that the expansion of the activity in question generated a greater concentration of land due to the increase in the number of large rural properties, migration of the rural population to urban areas, and also, it was unable to provide benefits for population from these locations, from the point of view of the socioeconomic indicators analyzed.

Keywords: Forestry. Producing municipalities. Socioeconomic transformation. Regional development.

\footnotetext{
${ }^{1}$ Universidade Estadual de Santa Cruz - UESC, Departamento de Ciências Econômicas (DCEC), Ilhéus (BA), Brasil, mpires@uesc.br, https://orcid.org/0000-0001-9036-514X.

2 Universidade Estadual de Santa Cruz - UESC, Departamento de Ciências Agrárias e Ambientais, Ilhéus (BA), Brasil, prof.pauloaguiar@bol.com.br, https://orcid.org/0000-0001-9578-9670.

${ }^{3}$ Universidade Estadual de Santa Cruz - UESC, Departamento de Ciências Agrárias e Ambientais, Ilhéus (BA), Brasil, erikagiuliaa@hotmail.com, https://orcid.org/0000-0001-5288-7342.
} 


\section{EFECTOS SOCIOECONÔMICOS DE LA CULTURA DE EUCALIPTO EN EL DESARROLLO DE MUNICIPIOS PRODUCTORES DE BAHIA, BRASIL}

Resumen: Este artículo tiene como objetivo analizar los efectos socioeconómicos del cultivo de eucalipto en el desarrollo de municipios productores en el estado de Bahía, Brasil. Como metodología, se realizó un análisis panorámico reciente de la producción de troncos para la producción de pulpa y papel en los principales estados productores brasileños; la caracterización de la silvicultura en el estado de Bahía; Las posibles influencias de la actividad en estudio sobre la economía de los municipios estudiados se identificaron mediante datos económicos y la estructura agraria; Las posibles transformaciones sociales en los municipios estudiados se analizaron a través de datos socioeconómicos. Según los resultados, se observa que la expansión de la actividad en cuestión generó una mayor concentración de tierra debido al aumento en el número de grandes propiedades rurales, la migración de la población rural a espacios urbanos, y no fue capaz de proporcionar beneficios a la población de estos lugares, desde el punto de vista de los indicadores socioeconómicos analizados.

Palabras clave: Silvicultura. Municipios produtores. Transformación socioeconómica. Desarrollo regional.

\section{Introdução}

A silvicultura, em seus distintos tipos, vem sendo desenvolvida em diferentes países do mundo e em muitos continentes. No continente europeu, por exemplo, a Finlândia se destaca, sendo a silvicultura a sua principal atividade agrícola (INVESTEXPORT BRASIL, 2015). Na América, Estados Unidos e Brasil assumem proeminência em razão do desenvolvimento e consolidação da atividade, posicionando-os como maiores produtores do mundo. E na Oceania, o destaque é a Austrália, que se posiciona entre os principais produtores mundiais.

Segundo Antonangelo e Bacha (1998), a história da silvicultura brasileira pode ser subdividida em três principais momentos. O primeiro, indo do descobrimento do país até o ano de 1965, caracterizando-se, sobretudo, por reflorestamentos de caráter científico ou ornamental. O segundo, entre os anos 1966 e 1988, quando houve a grande expansão de reflorestamentos decorrente de incentivos fiscais, mas sem preocupação com custo de produção, pois tais incentivos cobriam generosamente os custos até o quarto ano de implantação e condução das áreas plantadas. Por fim, o terceiro momento, a partir de 1989, caracterizando-se pela busca por eficiência (redução de custos e aumento da produtividade).

Nota-se, assim, conforme Viana (2004), que o reflorestamento em larga escala no Brasil se inicia na década de 1960, quando, em 1966, é sancionada a lei no 5.106, com o recolhimento de incentivos fiscais ao Fundo de Investimento 
Setorial, FISET Reflorestamento, e execução de projetos pelo Instituto Brasileiro de Desenvolvimento Florestal - IBDF.

Inicialmente, o reflorestamento concentrou-se nos estados de Minas Gerais, São Paulo, Paraná, Santa Catarina, Rio Grande do Sul e Mato Grosso do Sul. Nesses seis estados, existiam 97,33\% das árvores plantadas em 1970; e, em 1985, $88,76 \%$ das árvores plantadas (BACHA, 1993).

Atrelada a programas de incentivos fiscais, além de outros, expande-se a silvicultura no país, especialmente os programas públicos federais, como o de Reflorestamento de Pequenos e Médios Imóveis Rurais (REPEMIR), e estaduais, Programa Nacional de Papel e Celulose, Programa de Siderurgia a Carvão Vegetal e Programa de Substituição Energética, e também da iniciativa privada. (ANTONANGELO e BACHA, 1998).

Ao final do século $X X$ e as primeiras décadas do século $X X I$ ampliam-se os cultivos de eucalipto em razão de seu destaque econômico, em especial voltado para a produção de papel e celulose. Nesse cenário, o estado da Bahia já ocupava posição importante em nível nacional e internacional, detendo um dos maiores parques industriais do mundo para a produção de celulose de origem no eucalipto.

Em 2010, a Bahia ocupava a posição de segundo maior produtor de celulose de eucalipto no Brasil, com 14,7 milhões de metros cúbicos - m³ (SICM, 2014), e em 2014 passou à segunda posição no ranking nacional de produção de madeira em tora para papel e celulose, com 12.296.942 m³ (IBGE, 2015), cerca de 15\% do total produzido no país, ficando atrás apenas do estado de São Paulo, que foi responsável por $21 \%$ da produção de madeira em tora para papel e celulose.

No ano de 2014 os municípios brasileiros que lideraram o ranking nacional de produção de madeira em tora para celulose (pulpwood), de todas as espécies plantadas, segundo o IBGE (2015), foram, por ordem de relevância, Almeirim (Pará), Três Lagoas (Mato Grosso do Sul), Telêmeco Borba (Paraná), Brasilândia (Mato Grosso do Sul), Caravelas e Mucuri (Bahia), Aracruz (Espírito Santo) e Nova Viçosa (Bahia). Nota-se que três municípios baianos se encontravam entre os principais produtores em nível nacional.

Já no mercado de celulose, no ano de 2012 a produção baiana alcançou 2,8 milhões de toneladas, e 360 mil toneladas de papel, posicionando o estado como quarto maior produtor brasileiro nesse segmento (ABAF, 2013), evidenciando a importância da produção baiana de eucalipto e seus coprodutos, papel e celulose.

Do total de papel e celulose produzido na Bahia, a maior parte destina-se à 
demanda internacional, sendo os principais mercados destino da celulose a China e os Estados Unidos; e de papel, a Argentina e os Estados Unidos (MDIC, 2015).

No entanto, a despeito dessa produção e exportação gerar importantes divisas para o estado e para o país, apresenta pouco valor agregado, reforçando a posição do Brasil enquanto fornecedor essencialmente de matérias-primas para o mercado internacional. Além disso, os custos resultantes dessa produção, sobretudo os ambientais, muitas vezes não computados, constituem-se em externalidades negativas, que permanecem no local de produção, constituindo-se um "passivo" de responsabilidade "apenas" do produtor dessa matéria-prima.

Ademais, nas últimas décadas, a silvicultura baiana tem se transformado em cultivos em larga escala, tornando a paisagem rural de muitos municípios em um monocultivo. Associado a isso, como importante parte da produção segue para exportação, crises internacionais e mudanças cambiais geram fortes instabilidades, afetando diretamente a dinâmica econômica dos municípios produtores, sobretudo na circulação de capital, geração de renda e emprego. Tal realidade é comum nos principais municípios produtores de eucalipto para papel e celulose no Extremo Sul da Bahia, a qual é a principal produtora no estado.

Diante desse cenário, duas questões importantes se colocam como passíveis de averiguação: a primeira é identificar a contribuição para o desenvolvimento econômico local da produção de eucalipto em nível dos municípios produtores. A segunda é verificar se a expansão da produção de eucalipto, especificamente do segmento de papel e celulose, tem se traduzido em desenvolvimento para a região. Sendo assim, o principal objetivo deste artigo é analisar os efeitos socioeconômicos do cultivo de eucalipto no desenvolvimento de municípios produtores, no estado da Bahia, Brasil.

Como metodologia norteadora da pesquisa, um conjunto de técnicas e procedimentos foi seguido, os quais são especificados a seguir, visando responder às questões de pesquisa e ao principal objetivo proposto.

Primeiramente fez-se análise panorâmica da produção de madeira em tora para papel e celulose nos principais estados brasileiros produtores, a partir de levantamento e interpretação de dados secundários, junto ao Instituto Brasileiro de Geografia e Estatística - IBGE, com a finalidade de contextualizar o objeto de estudo na dinâmica do contexto nacional.

Em seguida, fez-se caracterização da silvicultura no estado da Bahia, apresentando a evolução da produção de madeira em tora para papel e celulose 
relativa ao período de 1990 a 2014, e 2015 a 2018, a partir de dados levantados junto ao IBGE. Para analisar o comportamento evolutivo das variáveis produção e área, aplicou-se o cálculo da Taxa Geométrica de Crescimento (TGC), relativa ao período 1990 a 2014, conforme Henderson e Quandt (1988):

$$
y=\alpha(1+r)^{x} \varepsilon
$$

Linearizou a função por meio da aplicação da logaritmização para cada variável:

$$
\log y=\log \alpha+[\log (1+r)] X+\log \varepsilon
$$

Fazendo-se $\log y=Y, \log \alpha=\beta_{0}, \log (1+r)=\beta_{1}$ e $\log \varepsilon=\mu$. A partir daí temse a função:

$$
Y=\beta_{0}+\beta_{1} X+\mu
$$

em que, $Y$ é o logaritmo da variável dependente a ser estimada (produção de madeira em tora para papel e celulose e população dos municípios), $\beta_{0}$ e $\beta_{1}$ os coeficientes estimados, $\mathrm{X}$ representa o tempo, em anos, e $\mu$ é o erro aleatório.

Como $\beta_{1}=\log (1+r)$, a TGC $(r)$ dada por:

$$
r=\operatorname{antilog}\left(\beta_{1}\right)-1
$$

Multiplicando-se o valor de $r$ por 100, obtém-se a TGC em termos percentuais. Considerou-se um nível de significância de $5 \%$, pelo teste $\mathbf{t}$ de Student, para o parâmetro $\beta_{1}$.

Com a finalidade de identificar as influências do cultivo de eucalipto sobre a economia e a paisagem agrícola dos municípios, foram levantados dados do produto interno bruto (PIB) para os anos 2000, 2010, 2012, 2014 e 2017, participação dos setores no PIB total para os anos 2000, 2014, 2015 e 2017 do IBGE, as áreas totais em hectares (ha) destinadas à produção de eucalipto, valor da produção de madeira em tora para o ano de 2017 do Censo Agropecuário do IBGE e número e área total dos estabelecimentos agropecuários para os anos censitários de 2006 e 2017.

Para as análises acerca dos aspectos sociais dos municípios estudados, levaram-se em consideração os seguintes dados: PIB per capita (anos 2000, 2010, 2012, 2014 e 2017) e Índice de Desenvolvimento Humano Municipal (IDH-M) publicados no Atlas de Desenvolvimento Humano no Brasil do PNUD para os anos censitários de 1991, 2000 e 2010; Índice de Gini renda dos municípios publicado no IBGE e Superintendência de Estudos Econômicos e Sociais da Bahia - SEI (anos1991, 2000 e 2010); Índice de Vulnerabilidade Social ${ }^{4}$ (anos 2000 e 2010) no

\footnotetext{
${ }^{4} \mathrm{O}$ Índice de Vulnerabilidade Social (IVS) é um indicador que varia entre 0 e 1 , sendo que, quanto mais próximo de 1, maior a vulnerabilidade, mais próximo de 0 menor é a vulnerabilidade. Esse índice
} 
site do Instituto de Pesquisas Econômicas Aplicadas - IPEA; e população rural, urbana e total (anos censitários 1991, 2000 e 2010), disponíveis no Atlas de Desenvolvimento Humano no Brasil do PNUD.

\section{A Produção brasileira e baiana de madeira em tora para papel e celulose}

Segundo Carriello e Vicens (2011), as primeiras mudas de eucalipto foram introduzidas no Brasil no século XIX, por Edmundo Navarro, com a intenção de produzir dormentes para as estradas de ferro. No entanto, a produção comercial mais intensiva só vai ocorrer aproximadamente no ano de 1903, na região de Rio Claro, São Paulo, para suprir a demanda por madeira da Companhia Paulista de Estrada de Ferro, o que levou a região a ser conhecida como o "berço do eucalipto".

Inicialmente, as pesquisas, de acordo com Martini (2004), centraram-se em identificar uma espécie vegetal que melhor se adaptasse às condições locais de produção para suprir às necessidades das ferrovias. Assim, buscava-se obter uma espécie que permitisse suprir a demanda por carvão e dormentes. Daí se expande os cultivos de eucalipto. Porém, os plantios em larga escala no Brasil só ocorrem, efetivamente, a partir da década de 1960, acentuando-se na década de 1970. Isso decorre das políticas de incentivo, e investimentos das indústrias de papel e celulose e siderurgia, gerando assim o desenvolvimento de tecnologias como o plantio clonal de eucalipto. O resultado foi o aumento substancial da produtividade florestal do país à época (CÂMARA SETORIAL da SILVICULTURA, 2009; CERQUEIRA Neto, 2012).

O surgimento dos clones de eucalipto na década de 1970 permitiu reduzir a heterogeneidade dos cultivos e da incidência de doenças nos plantios (XAVIER e

\footnotetext{
possui as seguintes escalas: de 0 a 0,200 , "muito baixa vulnerabilidade" social; de 0,201 a 0,300, "baixa vulnerabilidade"; de 0,301 a 0,400, "média vulnerabilidade"; de 0,401 a 0,500, "alta vulnerabilidade"; e de 0,501 a 1, "muito alta vulnerabilidade" (IPEA, 2015). Esse indicador é composto em: a) Infraestrutura Urbana a qual é decomposta em quatro variáveis: porcentagem da população em domicílios com energia elétrica; porcentagem da população em domicílios com densidade $>2$; porcentagem de pessoas em domicílios com abastecimento de água e esgotamento sanitário inadequados; e porcentagem de vulneráveis que gastam mais de uma hora até o trabalho na população ocupada; b) Capital Humano é a variável do IVS que engloba oito variáveis: mortalidade infantil; porcentagem de mulheres de 10 a 17 anos que tiveram filhos; porcentagem de mães chefes de família sem fundamental e com filho menor, no total de mães chefes de família; porcentagem de crianças em municípios onde ninguém tem fundamental completo; porcentagem de crianças de 0 a 5 anos fora da escola; porcentagem de crianças de 6 a 14 anos fora da escola; porcentagem de pessoas de 15 a 24 anos que não estudam, não trabalham e são vulneráveis, na população dessa faixa; e taxa de analfabetismo - 15 anos ou mais; c) Renda e trabalho, composta de cinco variáveis: porcentagem de renda domiciliar per capita igual ou inferior a $R \$ 255,00$; taxa de atividade -10 a 14 anos; taxa de desocupação - 18 anos ou mais; porcentagem de pessoas de 18 anos ou mais sem fundamental completo e em ocupação informal; e porcentagem de vulneráveis e dependentes de idosos.
} 
SILVA, 2010). Entre as décadas de 1980 e 1990 os plantios se expandem para estados do Sul e outros do Sudeste brasileiro (norte do Espírito Santo), chegando então à Bahia (CERQUEIRA Neto, 2012).

Segundo a Associação Brasileira de Celulose e Papel (BRACELPA, 2014), quase toda produção de papel brasileira tem sua origem na celulose de fibra curta, de eucalipto ou pinus, conforme o mercado destino. O cultivo de eucalipto se adaptou bem às condições edafoclimáticas no Brasil, levando o país a ser competitivo no mercado internacional, ao apresentar um dos menores tempos de rotação do cultivo e maiores rendimentos hectare/ano. Enquanto no Brasil a rotação do eucalipto é de 7 anos, na Espanha, são 12 a 15 anos. Outras espécies de fibra curta, como a bétula produzida na Suécia e na Finlândia, tem uma rotação entre 35 a 40 anos (BRACELPA, 2014; CETESB, 2008). Segundo Puitel et al. (2014), a competitividade brasileira na fabricação de papel se assenta na redução de custos e cumprimento de indicadores ambientais, sendo o consumo de água o principal.

$\mathrm{Na}$ Bahia, segundo a Federação das Indústrias do Estado da Bahia (FIEB, 2014), as exportações de celulose e papel, produtos minerais, produtos da indústria química, têxteis, metais, automóveis, café e soja, são as mais relevantes na balança comercial. Nesse computo, as exportações baianas de papel e celulose alcançaram US\$1,67 bilhão em 2010, levando o estado a ocupar a segunda posição no ranking de exportações do Brasil (SICM, 2014).

$\mathrm{Na}$ organização industrial do setor florestal a produção é separada em produtos madeireiros e não madeireiros, e, conforme o grau de processamento, surge os mais diversos produtos (BIAZUS et al., 2011). Inicialmente a madeira é transformada em tora e madeira serrada, e a partir dessa última, obtém-se a celulose, e do processamento da celulose tem-se o papel (BIAZUS et al., 2011).

Entre os estados brasileiros que mais se destacam na produção de madeira em tora para papel e celulose encontra-se São Paulo, Bahia, Paraná, Pará, Mato Grosso do Sul, Minas Gerais, Santa Catarina, Espírito Santo e Rio Grande do Sul. Com base nos dados do ano de 2014, o agregado da produção desses estados representou mais de $90 \%$ da produção nacional (Gráfico 1). A produção da Bahia, que era inexpressiva em 1990, atingiu $15 \%$ do total da produção nacional no ano de 2014, levando o estado a ocupar a segunda posição no ranking nacional. Outro estado com expressivo crescimento na produção nacional é Mato Grosso do Sul, enquanto a maioria dos demais produtores brasileiros vem mantendo o mesmo perfil da produção, levando-os a reduzir sua participação percentual no total nacional. 
Gráfico 1- Quantidade produzida de madeira em tora para papel e celulose nos principais estados brasileiros (em \%), 1990 a $2014^{1}$

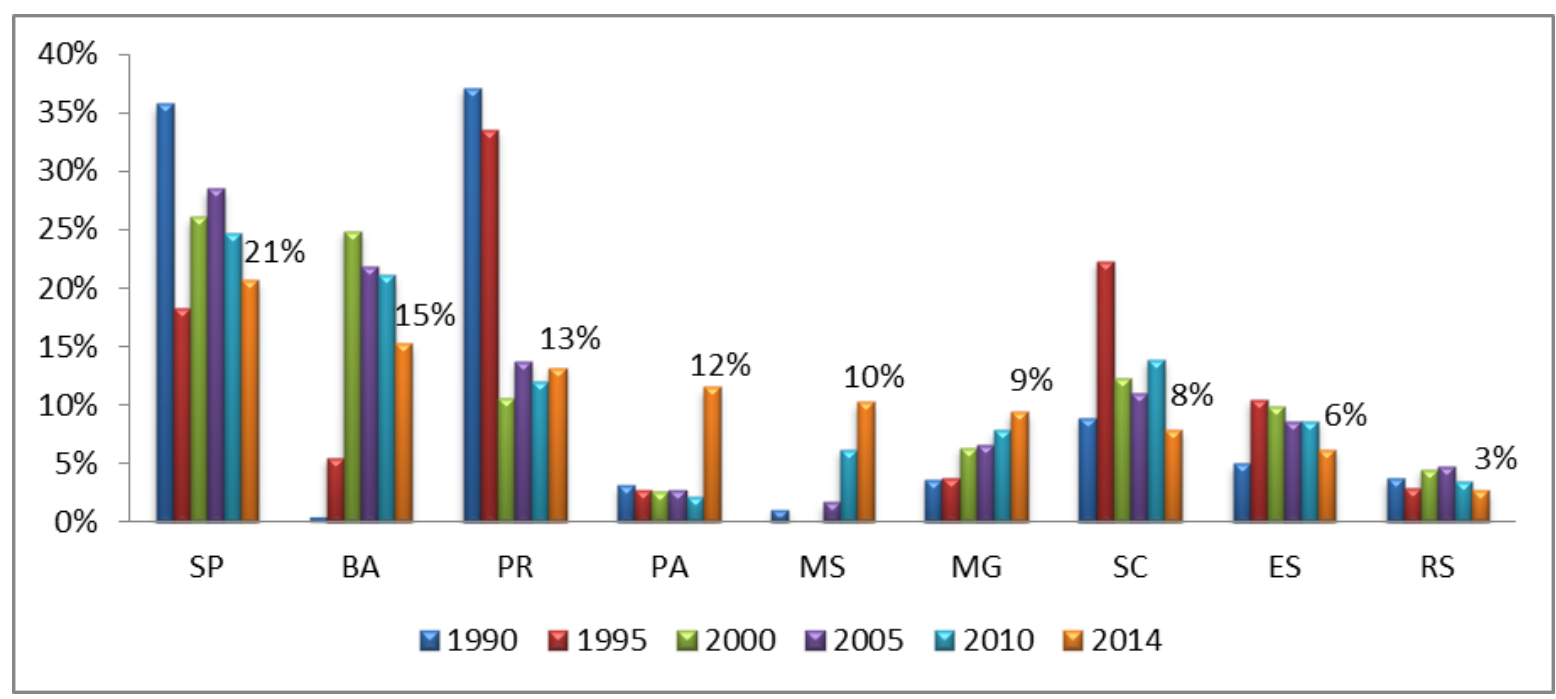

Fonte: Elaboração própria, dados do IBGE - Produção da Extração Vegetal e da Silvicultura (2015). Nota: ${ }^{1} \mathrm{SP}=$ São Paulo; BA = Bahia; PR = Paraná; PA = Pará; MS = Mato Grosso do Sul; MG = Minas Gerais; SC = Santa Cataria; ES = Espírito Santo; e RS = Rio grande do Sul.

As taxas de crescimento revelam que a produção brasileira de madeira em tora para papel e celulose cresceu 3,39\% ao ano entre o período de 1990 a 2014. São Paulo, maior produtor nacional, apesar de crescer, a sua taxa é menor, sendo 2,95\% a.a. A posição de destaque no cenário nacional deve-se ao seu pioneirismo no cultivo, além de ser um polo industrial nos segmentos papel e celulose, e possuir importante infraestrutura logística para atender à demanda interna e externa. No entanto, a despeito de em termos absoluto esse estado ser o maior produtor no período de 1990 a 2014, a sua participação diminuiu, passando de 36\% em 1990 para 21\% em 2014.

De forma diferente, a Bahia e Mato Grosso do Sul vêm ocupando lugar de destaque no cenário nacional, apresentando uma taxa de crescimento da produção em torno de $15 \%$ a.a. e $28 \%$ a.a., respectivamente, no período analisado. Até 2008 o estado do Mato Grosso do Sul representava apenas 1\% da produção do país, mas as inúmeras iniciativas públicas e privadas voltadas para o cultivo do eucalipto em sistemas agroflorestais (SAF) permitiram a evolução da atividade nesse estado.

No entanto, a Bahia, dentre os estados com produção registrada desde 1990, apresenta a maior taxa de crescimento. Tal fenômeno pode ser explicado pelas condições edafoclimáticas favoráveis na principal região produtora no estado (Neto 2012); e a facilidade de escoamento dos produtos, e incentivos fiscais concedidos. 
De forma geral, a taxa de crescimento da produção de madeira em tora para papel e celulose do Brasil e dos seus principais entes produtores, entre 1990 a 2014, foram: Brasil (3,39\%); São Paulo (2,95\%); Bahia (15,02\%); Paraná $(-0,88 \%)$; Pará $(3,61 \%)$; Mato Grosso do Sul (27,62\%); Minas Gerais (7,08\%); Santa Catarina (2,20\%); Espírito Santo (2,30\%); e Rio Grande do Sul (3,08\%). A produção refere-se ao total produzido de madeira em tora para papel e celulose, não diferenciando as espécies de árvore (eucalipto, pinus, dentre outras). Em 2013, 77,67\% do total de madeira em tora para papel e celulose produzido no Brasil era proveniente do eucalipto, em 2014 esse percentual passou para 83,58\%. Isso revela que a maior parte da madeira em tora para papel e celulose produzida nos estados é originada de eucalipto, exceção para Paraná e Santa Cantaria, onde se destaca o pinus.

Quanto à participação da Bahia na produção nacional, essa tem crescido substancialmente, sendo sua produção concentrada em nove municípios das regiões Sul e Extremo Sul do estado. Grande parte desse crescimento deveu-se ao aumento da produção nos municípios de Caravelas, Mucuri, Nova Viçosa, Santa Cruz Cabrália, Alcobaça, Teixeira de Freitas, Porto Seguro, Belmonte e Mascote. Nas estatísticas para o ano 1990, a produção baiana era irrelevante, no entanto em 2000 passa a responder por $1 / 4$ da produção nacional, e recentemente esse percentual está em torno de 15\% (Gráfico 2).

Gráfico 2- Participação do estado da Bahia na produção brasileira de madeira em tora para papel e celulose $\left(\mathrm{m}^{3}\right)$ entre os anos de 1990 a 2013

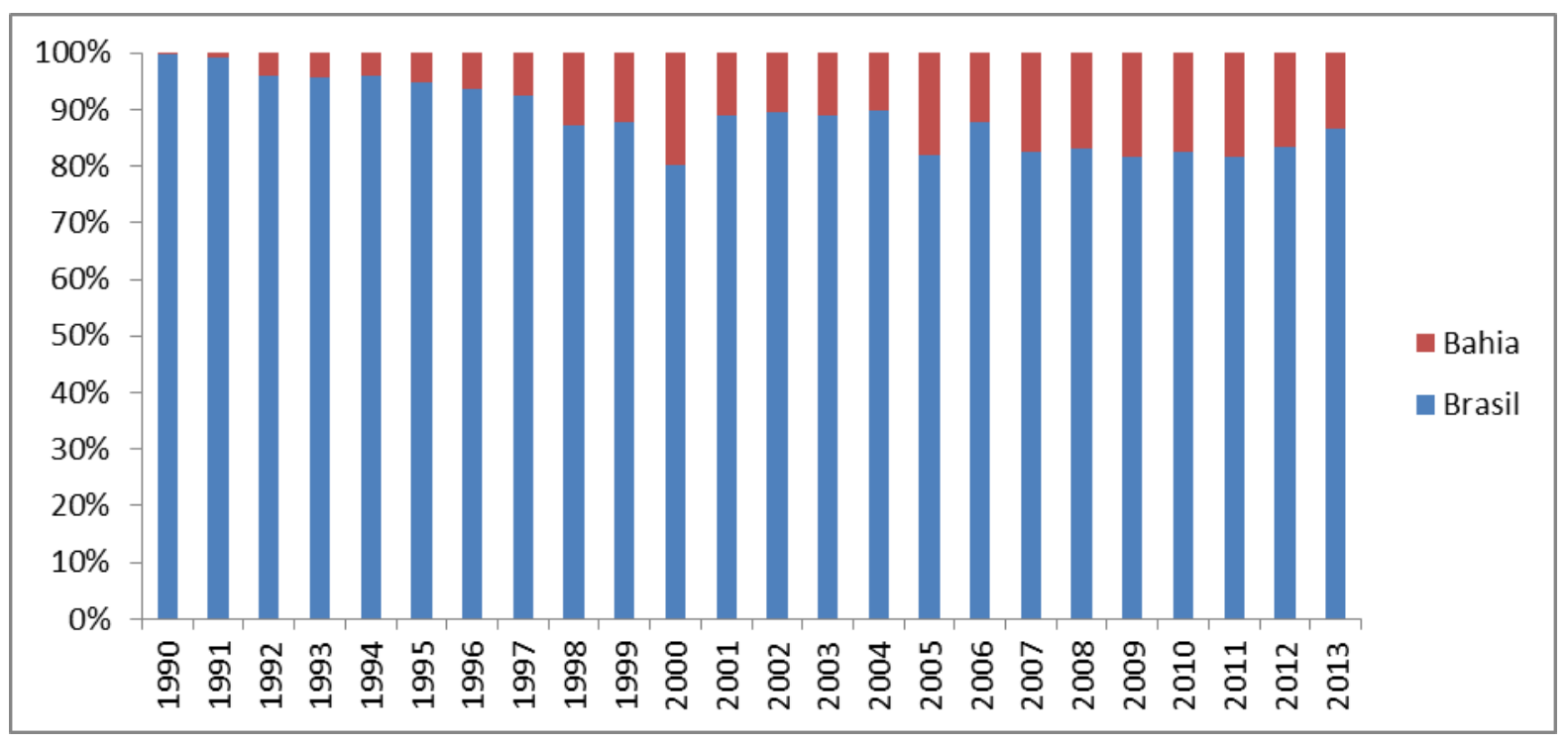

Fonte: Elaboração própria; dados do IBGE - Produção da Extração Vegetal e da Silvicultura (2015). 
Em âmbito nacional, um novo e importante impulso no setor foi dado com a inauguração, em março de 2014, de uma unidade da Fábrica da Suzano Papel e Celulose, no município de Imperatriz, estado do Maranhão, a qual já se encontrava em funcionamento desde dezembro de 2013, algo que colocaria esse estado na lista dos principais produtores do país a partir do ano de 2014. Até o ano de 2013 a produção do referido estado foi irrisória no computo nacional, não chegando próximo de $1 \%$ da produção brasileira; mas no ano de 2014 já representava 1,6\% desta. Nos anos de 2015, 2016 e 2017, sua produção representou apenas 1\% da produção nacional; e em 2018, passou a representar $2 \%$ desta (Gráfico 3).

Conforme se pode observar, por meio do Gráfico 3, a partir do ano de 20150 estado do Paraná assume e se mantém na primeira posição com maior representação percentual na produção nacional de madeira em tora para papel e celulose, com percentual de produção de 22\% nos anos 2015 e 2018, e 24\% nos anos 2016 e 2017. Já o estado de São Paulo cai para a segunda posição na representação percentual em relação à produção nacional, apresentando a tendência de contínuo declínio nessa representação entre os anos de 2015 a 2018. O estado da Bahia também apresentou queda em sua representação percentual em relação à produção nacional, deixando a segunda posição que ocupava no ano de 2014, passando a ocupar, no ano de 2018, a quinta posição, ficando atrás dos estados do Paraná, São Paulo, Santa Catarina e Mato Grosso do Sul.

Gráfico 3- Quantidade produzida de madeira em tora para papel e celulose nos principais estados brasileiros (em \%), 2015 a $2018^{2}$

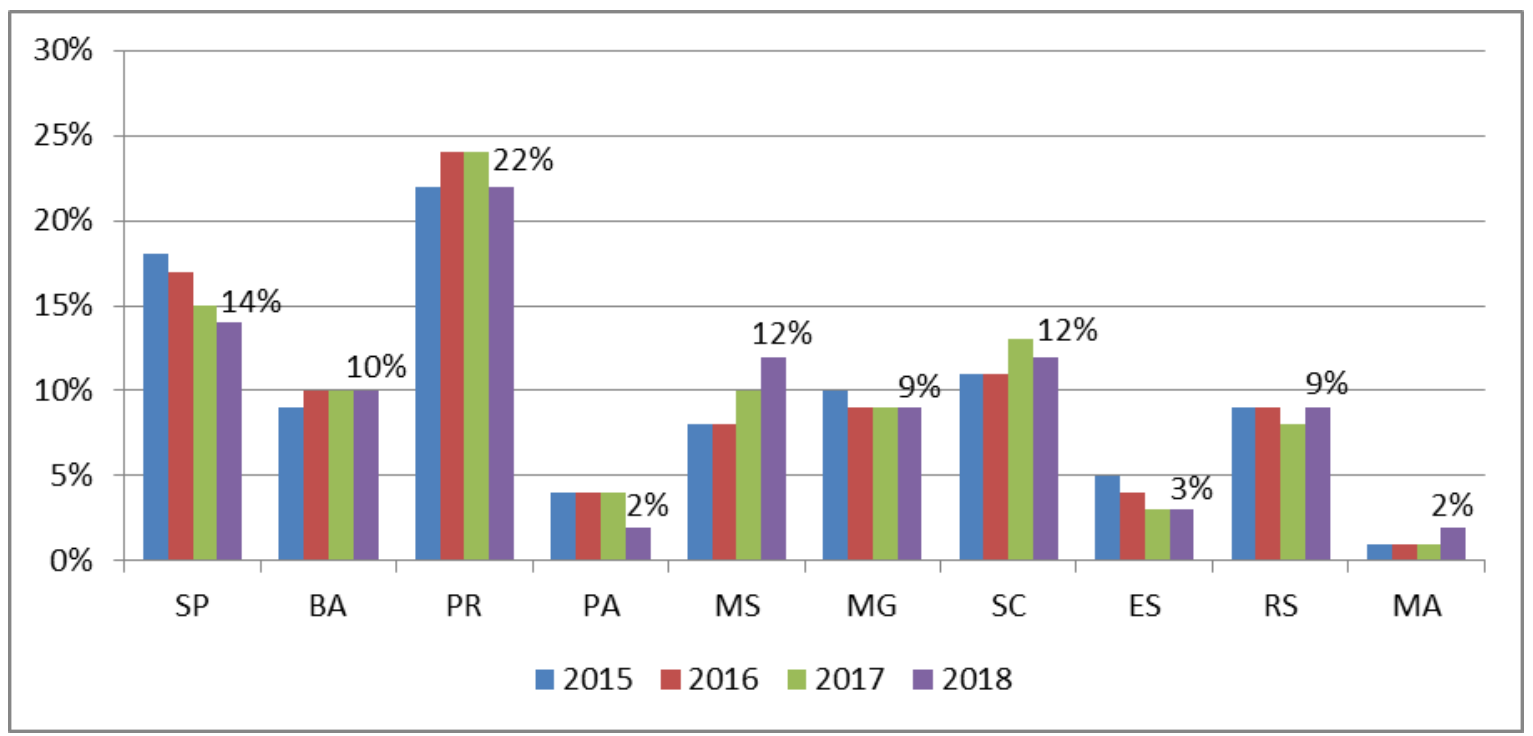

Fonte: Elaboração própria, dados do IBGE - Produção da Extração Vegetal e da Silvicultura (2019). Nota: ${ }^{2} \mathrm{SP}=$ São Paulo; BA = Bahia; PR = Paraná; PA = Pará; MS = Mato Grosso do Sul; MG = Minas Gerais; SC = Santa Cataria; ES = Espírito Santo; RS = Rio grande do Sul; e MA = Maranhão. 
Nos anos de 2015 e 2016, os valores absolutos da produção de madeira em tora para papel e celulose dos estados do Paraná, São Paulo, Santa Catarina, Mato Grosso do Sul, Bahia, Minas Gerais, Rio Grande do Sul, Espírito Santo, Pará e Maranhão, representaram, de forma conjunta, aproximadamente $98 \%$ da produção nacional; no ano de 2017, representaram 96\%; e no ano 2018, representaram, aproximadamente, 96\%. Em 2015, a produção agregada desses estados foi de 121.213.318 metros cúbicos $\left(\mathrm{m}^{3}\right)$; e a do Brasil, foi de 123.868.472m³. Em 2016, os citados estados produziram, de forma agregada, $132.575 .511 \mathrm{~m}^{3}$; e o Brasil, $135.407 .675 \mathrm{~m}^{3}$. Já em 2017 , produziram $133.290 .637 \mathrm{~m}^{3}$; e a produção nacional foi de 138.735.624. Por fim, em 2018 os mencionados estados produziram, de forma agregada, $141.838 .661 \mathrm{~m}^{3}$; e o Brasil, $146.463 .834 \mathrm{~m}^{3}$ (IBGE, 2019).

\section{Implicações socioeconômicas da produção de madeira em tora para celulose e papel nos municípios}

A área geográfica levada em consideração no presente estudo abrange nove municípios no estado da Bahia, os quais foram identificados como sendo os maiores produtores de madeira em tora para a produção de papel e celulose no ano de $2014^{5}$, os quais representavam $70 \%$ da produção estadual (Figura 1). Esses municípios estão dispersos em três territórios de identidade ${ }^{6}$ : Território de Identidade Litoral Sul (Mascote), três no Território de Identidade Costa do Descobrimento (Belmonte, Santa Cruz Cabrália e Porto Seguro), e cinco no Território de Identidade Extremo Sul (Caravelas, Mucuri, Nova Viçosa, Alcobaça e Teixeira de Freitas). Excluiu-se o município de Eunápolis, pois no ano de 2014 os dados do IBGE (2015) não o posicionavam no rol de municípios responsáveis por 70\% da produção baiana.

As áreas territoriais que abrangem os municípios baianos estudados, originalmente eram cobertas predominantemente pela Mata Atlântica. No entanto, a extração da madeira, desde o período colonial, era uma realidade vigente por conta da importância econômica de inúmeros tipos de madeira presentes nesses locais. A inserção de cultivos como cacau, e mais recentemente café, introduziram nova dinâmica econômica; mesmo assim esses municípios não se encontravam integrados à dinâmica nacional. A despeito disso, a extração de madeira continuou e no século XX adquiriu novo impulso, sobretudo pela instalação de grandes

\footnotetext{
${ }^{5}$ Este artigo é fruto de uma dissertação de mestrado já defendida, cujo ano base para a escolha dos municípios que representavam $70 \%$ da produção baiana foi 2014. Neste artigo, conquanto tenha-se mantido o ano de 2014 como base para escolha dos municípios, no entanto, para alguns indicadores analisados para essas espacialidades acrescentaram-se dados e atualizaram-se outros.

${ }^{6}$ Regionalização adotada pelo Governo do Estado da Bahia.
} 
madeireiras nas regiões Sul e Extremo Sul da Bahia, gerando forte pressão sobre a paisagem baiana da Mata Atlântica, favorecida ainda pela construção da BR 101 nessa porção do território estadual, levando-a a se incorporar mais diretamente à dinâmica econômica nacional.

Figura 1- Localização dos municípios maiores produtores de Eucalipto no Estado da Bahia, Brasil (listagem por ordem alfabética), em 2014

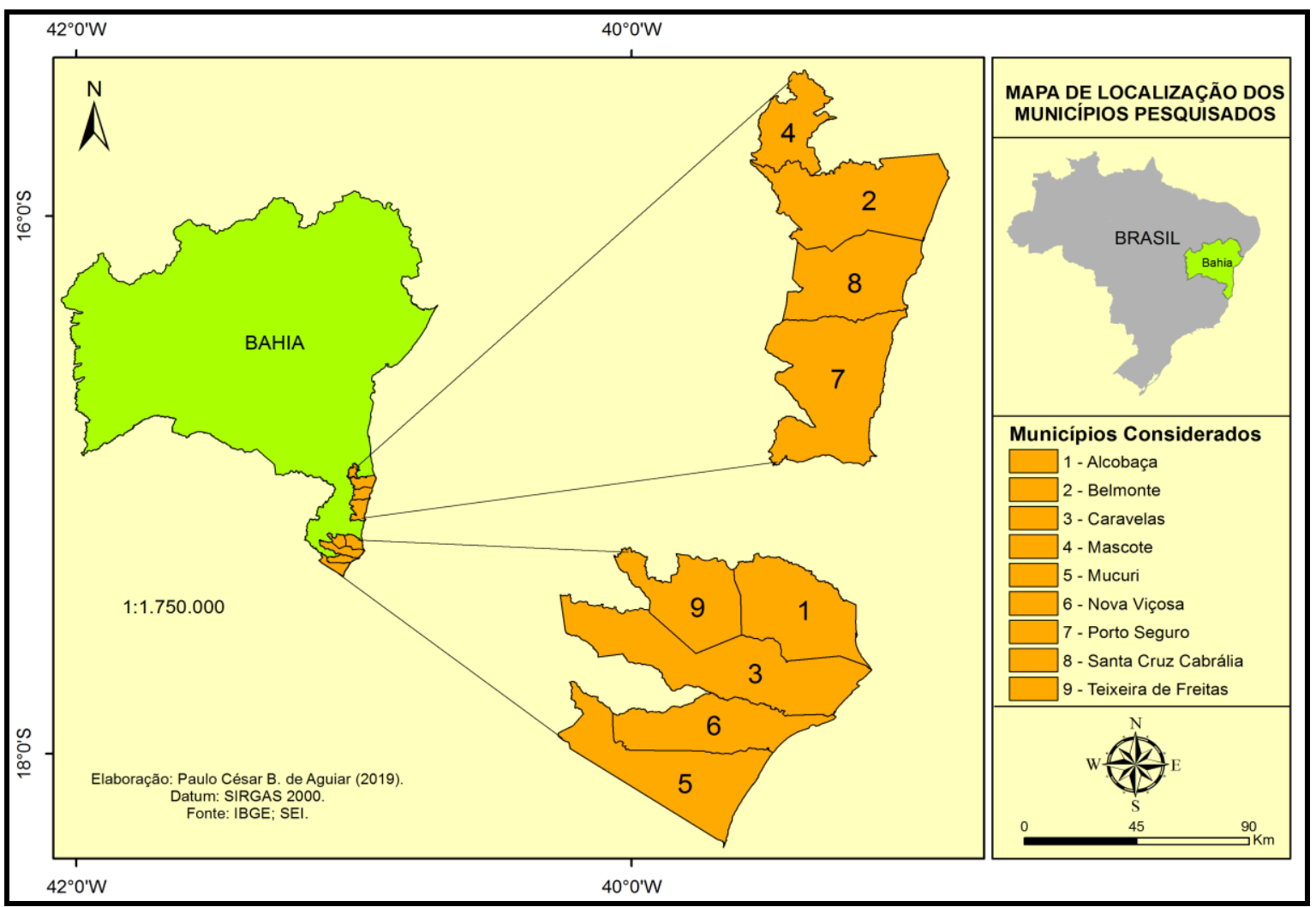

Elaboração própria: AGUIAR, P. C. B. de, a partir de SEI/IBGE (2000).

Segundo Silva e Mendonça (2000), três períodos podem ser apontados como de grande pressão sobre a Mata Atlântica no transcurso do século XX, nas áreas analisadas neste trabalho. De 1948 a 1952, instalam-se madeireiras de grande porte, a ELECUNHA S/A no município de Nova Viçosa, e a BRALANDA no município de Medeiros Neto. De 1955 a 1965, chegam de Minas Gerais e do Espírito Santo exploradores de madeira, especialmente de jacarandá, degradando a floresta e os solos, e praticando queimadas indiscriminadas. De 1970 a 1980, com a construção da BR 101, potencializou-se o maior período de devastação da Mata Atlântica, quando são instaladas mais de 50 indústrias de madeira e serrarias às margens da rodovia, sobretudo no município de Itabela, e, posteriormente, destinando essas áreas para a pecuária extensiva. 
No entanto, as fiscalizações ambientais e os incentivos governamentais para o reflorestamento e desenvolvimento da silvicultura geraram redução daquelas empresas e o surgimento de empresas florestais, como Vera Cruz Florestal, Aracruz Celulose, Bahia Sul Celulose, Veracel. As atividades desenvolvidas por essas empresas ligadas à atividade silvicultural propiciaram a integração local e potencializaram uma reorganização socioeconômica e espacial nessas áreas.

No que concerne aos nove municípios considerados nesta análise, percebese que no ano de 1990 (Tabela 1) não há registro de produção de madeira em tora para papel e celulose, o que pode ter ocorrido em função da pouca expressividade local da atividade. Porém, gradativamente a produção se expande para novos espaços, áreas agricultáveis de pequenos cultivos, via parceria com proprietários de terra para plantio de eucalipto ou arrendamento da terra. Tais estratégias fazem com que se agreguem mais áreas destinadas à produção de eucalipto entre 1990 a 2014.

Os primeiros registros foram observados nos municípios de Alcobaça e Caravelas, em seguida em Mucuri, Nova Viçosa e Teixeira de Freitas. Em 2002 outros municípios passaram a produzir eucalipto, a exemplo de Belmonte, Porto Seguro e Santa Cruz Cabrália; e, em 2013, Mascote, completando o rol dos municípios. Nota-se que Mascote teve o crescimento mais expressivo da produção, embora sua produção seja bem recente. Mucuri, Teixeira de Freitas e Belmonte, que possuem parques produtivos já consolidados, registrou crescimento da produção em percentuais superiores à média da Bahia. A produção anual de madeira em tora (eucalipto) de cada município apresentou comportamento cíclico, com aumentos, estagnação e declínios (Tabela 1), explicado pelos ciclos de produção, que envolvem plantio, desenvolvimento da espécie e corte, e período para que a área novamente seja disponibilizada para novos plantios, e, assim, ao atingir a idade de sete anos, iniciarem o corte.

Para o ano de 2014, nove municípios responderam por 69\% da produção estadual de madeira em tora para papel e celulose, destacando-se Caravelas, Mucuri e Nova Viçosa, com, respectivamente, 14\%, 11\% e 10\%, seguidos de Santa Cruz Cabrália (8\%), Alcobaça (7\%), Teixeira de Freitas (6\%), Porto Seguro (5\%), Belmonte (4\%) e Mascote (4\%). O restante da produção estadual (31\%) está dispersa em municípios com participação inferior a 4\% (IBGE, 2015). 
Tabela 1- Quantidade produzida de madeira em tora para papel e celulose $\left(\mathrm{em} \mathrm{m}^{3}\right)$, Bahia e principais municípios baianos produtores, e TGC (\%) da produção, entre 1990 a 2014, e quantidade produzida de madeira em tora para papel e celulose $\left(\mathrm{em} \mathrm{m}^{3}\right)$ entre 2015 a 2018

Continua

\begin{tabular}{|c|c|c|c|c|c|c|}
\hline Ano & Alcobaça & Belmonte & Caravelas & Mascote & Mucuri & Bahia \\
\hline 1990 & - & - & & 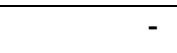 & - & 121.707 \\
\hline 1991 & 75.506 & - & 273.673 & - & - & 352.088 \\
\hline 1992 & 325.529 & - & 446.347 & - & 53.321 & 1.609 .790 \\
\hline 1993 & 408.296 & - & 720.714 & - & 108.171 & 1.912 .501 \\
\hline 1994 & 511.605 & - & 474.974 & - & 11.510 & 2.186 .702 \\
\hline 1995 & 395.905 & - & 606.086 & - & 19.700 & 2.646 .807 \\
\hline 1996 & 209.948 & - & 536.655 & - & 13.262 & 2.265.798 \\
\hline 1997 & 133.407 & - & 565.675 & - & 596.948 & 2.879 .703 \\
\hline 1998 & 1.053 .106 & - & 1.872 .867 & - & 1.245 .806 & 5.753 .001 \\
\hline 1999 & 973.013 & - & 1.216 .273 & - & 2.204 .254 & 5.707 .117 \\
\hline 2000 & 1.135 .081 & - & 1.487 .540 & - & 2.643 .836 & 11.436 .517 \\
\hline 2001 & 1.319 .526 & - & 644.469 & - & 1.186 .784 & 5.133 .429 \\
\hline 2002 & 609.386 & 41.591 & 315.032 & - & 699.199 & 5.135 .648 \\
\hline 2003 & 116.546 & 41.591 & 1.269 .125 & - & 886.529 & 6.219 .340 \\
\hline 2004 & 350.866 & 4.970 & 808.096 & - & 1.518 .050 & 5.318 .263 \\
\hline 2005 & 1.502 .205 & 110.510 & 1.971 .852 & - & 4.456 .540 & 11.973 .906 \\
\hline 2006 & - & 135.707 & - & - & 1.805 .429 & 7.582 .995 \\
\hline 2007 & 2.012 .592 & 595.385 & 1.450 .963 & - & 2.490 .019 & 12.904 .448 \\
\hline 2008 & 1.318 .436 & 486.474 & 1.707 .499 & - & 1.728 .489 & 11.924 .025 \\
\hline 2009 & 997.411 & 849.297 & 2.707 .092 & - & 2.812 .156 & 14.674 .553 \\
\hline 2010 & 1.091 .253 & 253.948 & 2.299 .345 & - & 2.050 .254 & 14.707 .593 \\
\hline 2011 & 2.442 .826 & 260.200 & 3.719 .102 & - & 1.881 .008 & 17.187 .851 \\
\hline 2012 & 1.684 .059 & 1.174 .585 & 2.170 .116 & - & 2.162 .383 & 14.691 .841 \\
\hline 2013 & 887.201 & 952.584 & 1.176 .101 & 58.075 & 902.941 & 11.182 .710 \\
\hline 2014 & 911.024 & 539.781 & 1.772 .598 & 536.977 & 1.361 .040 & 12.296 .942 \\
\hline TGC & $9,00 \%$ & $36,83 \%$ & $7,95 \%$ & $824,62 \%^{1}$ & $20,58 \%$ & $15,02 \%$ \\
\hline 2015 & 743.204 & 945.330 & 1.344 .527 & 255.911 & 1.210 .418 & 11.367 .122 \\
\hline 2016 & 949.090 & 517.495 & 1.946 .356 & 446.192 & 1.876 .225 & 14.051 .768 \\
\hline 2017 & 931.793 & 330.474 & 2.222.286 & 35.631 & 1.803 .776 & 13.318 .036 \\
\hline 2018 & 1.277 .700 & 734.207 & 2.376.922 & 8.326 & 1.647 .432 & 14.112 .072 \\
\hline
\end{tabular}

Fonte: IBGE - Produção da Extração Vegetal e da silvicultura (2019).

${ }^{1}$ Não significativo. 
Tabela 1- Quantidade produzida de madeira em tora para papel e celulose $\left(\mathrm{em} \mathrm{m}^{3}\right)$, Bahia e principais municípios baianos produtores, e TGC (\%) da produção, entre 1990 a 2014, e quantidade produzida de madeira em tora para papel e celulose (em m³) entre 2015 a 2018

\begin{tabular}{|c|c|c|c|c|c|}
\hline Ano & Nova Viçosa & Porto Seguro & Santa Cruz Cabrália & Teixeira de Freitas & Bahia \\
\hline 1990 & - & & - & - & 121.707 \\
\hline 1991 & - & - & - & - & 352.088 \\
\hline 1992 & 301.519 & - & - & 6.315 & 1.609 .790 \\
\hline 1993 & 463.098 & - & - & 1.344 & 1.912 .501 \\
\hline 1994 & 614.760 & - & - & 382 & 2.186 .702 \\
\hline 1995 & 691.881 & - & - & 39.194 & 2.646 .807 \\
\hline 1996 & 953.620 & - & - & 1.218 & 2.265 .798 \\
\hline 1997 & 629.317 & - & - & 30.414 & 2.879 .703 \\
\hline 1998 & 513.781 & - & - & 24.296 & 5.753 .001 \\
\hline 1999 & 713.822 & - & - & 390 & 5.707 .117 \\
\hline 2000 & 462.386 & - & - & 19.392 & 11.436 .517 \\
\hline 2001 & 463.686 & - & - & - & 5.133 .429 \\
\hline 2002 & 1.327 .204 & 190.971 & 524.241 & 93.387 & 5.135 .648 \\
\hline 2003 & 1.678 .760 & 190.971 & 524.241 & - & 6.219 .340 \\
\hline 2004 & 662.609 & 767.182 & 816.544 & - & 5.318 .263 \\
\hline 2005 & 937.078 & 449.794 & 620.555 & 167.908 & 11.973 .906 \\
\hline 2006 & 837.412 & 497.784 & 1.026 .211 & 248.200 & 7.582 .995 \\
\hline 2007 & 1.185 .485 & 526.767 & 1.037 .550 & 170.018 & 12.904 .448 \\
\hline 2008 & 2.350 .058 & 336.980 & 418.745 & 115.401 & 11.924 .025 \\
\hline 2009 & 1.768 .640 & 114.772 & 469.587 & 362.529 & 14.674 .553 \\
\hline 2010 & 1.929 .476 & 427.728 & 1.797 .585 & 483.356 & 14.707 .593 \\
\hline 2011 & 1.787 .019 & 440.500 & 1.850 .000 & 343.512 & 17.187 .851 \\
\hline 2012 & 1.497 .561 & 1.026 .170 & 868.435 & 637.948 & 14.691 .841 \\
\hline 2013 & 1.437 .405 & 526.410 & 358.159 & 315.356 & 11.182 .710 \\
\hline 2014 & 1.256 .213 & 621.889 & 955.501 & 679.775 & 12.296 .942 \\
\hline TGC & $6,72 \%$ & $6,48 \%$ & $3,09 \%$ & $33,08 \%$ & $15,02 \%$ \\
\hline 2015 & 880.729 & 533.745 & 426.945 & 198.584 & 11.367 .122 \\
\hline 2016 & 1.517 .124 & 442.350 & 651.546 & 364.571 & 14.051 .768 \\
\hline 2017 & 1.281 .120 & 225.466 & 1.171 .703 & 120.227 & 13.318 .036 \\
\hline 2018 & 1.565 .829 & 727.422 & 988.821 & 321.308 & 14.112 .072 \\
\hline
\end{tabular}

Fonte: IBGE - Produção da Extração Vegetal e da silvicultura (2019). 
Já no ano de 2015, os nove municípios considerados foram responsáveis por $57 \%$ da produção estadual baiana de madeira em tora para papel e celulose, representando uma queda de $12 \%$ em relação à participação percentual que exerciam no ano de 2014. Por sua vez, no ano de 2018 os nove municípios representaram, de forma conjunta, $68 \%$ da produção estadual.

Esse aumento expressivo da produção de madeira em tora para produção de papel e celulose gerou efeitos positivos sobre o PIB dos municípios, o qual apresentou tendência de aumento do ano 2000 ao ano de 2017 (Tabela 2), sendo os aumentos mais expressivos em Mucuri, Teixeira de Freitas, Porto Seguro e Nova Viçosa. A atividade tornou-se uma das mais relevantes para as economias dos municípios, potencializando direta e indiretamente outras atividades econômicas, especialmente no setor de serviços associados à produção de eucalipto.

Tabela 2- Produto Interno Bruto, PIB-M, em reais, dos municípios pesquisados, nos anos 2000, 2010, 2012, 2014 e 2017.

\begin{tabular}{l|r|r|r|r|r}
\hline \multirow{2}{*}{ Município } & \multicolumn{6}{|c}{ PIB dos municípios (R\$) X 1000 } \\
\cline { 2 - 6 } & \multicolumn{1}{|c|}{$\mathbf{2 0 0 0}$} & $\mathbf{2 0 1 0}$ & $\mathbf{2 0 1 2}$ & $\mathbf{2 0 1 4}$ & \multicolumn{1}{c}{$\mathbf{2 0 1 7}$} \\
\hline Alcobaça & $65.528,00$ & $179.465,00$ & $193.453,00$ & $209.489,00$ & $264.120,87$ \\
Belmonte & $34.148,00$ & $165.245,00$ & $208.451,00$ & $229.954,00$ & $265.473,32$ \\
Caravelas & $85.864,00$ & $262.803,00$ & $283.502,00$ & $285.985,00$ & $322.126,33$ \\
Mascote & $17.690,00$ & $72.499,00$ & $89.774,00$ & $116.793,00$ & $149.808,56$ \\
Mucuri & $408.970,00$ & $1.264 .665,00$ & $1.195 .332,00$ & $1.357 .371,00$ & $1.976 .299,13$ \\
Nova Viçosa & $80.731,00$ & $273.964,00$ & $323.819,00$ & $399.216,00$ & $480.306,26$ \\
Porto Seguro & $234.838,00$ & $1.181 .263,00$ & $1.514 .841,00$ & $2.077 .893,00$ & $2.820 .578,22$ \\
Santa Cruz Cabrália & $46.988,00$ & $172.354,00$ & $212.967,00$ & $275.955,00$ & $394.545,45$ \\
Teixeira de Freitas & $282.335,00$ & $1.302 .925,00$ & $1.512 .014,00$ & $1.939 .606,00$ & $2.311 .886,16$ \\
\hline
\end{tabular}

Fonte: IBGE/DATASUS. Disponível em: <http://www.deepask.com/goes?page=alcobaca/BA-Confirao-PIB---Produto-Interno-Bruto---no-seu-municipio> Acesso em: 05/08/2019.

Conforme se pode observar por meio da tabela 3, a participação dos setores na composição do PIB dos nove municípios evidencia que no ano 2000 a agropecuária predominava como principal setor apenas em Alcobaça e Caravelas; enquanto 0 setor de serviços ${ }^{7}$ predominava para os sete restantes, exceção de Mucuri que tem no setor industrial sua principal geração de riqueza, pois lá se encontra a empresa Suzano Papel e Celulose S.A.

Para o ano de 2014, quando se exclui do PIB de serviços a participação da administração pública, observa-se que entre os três setores de atividades (agropecuária, indústria e serviços), apenas nos municípios de Caravelas e Mascote

\footnotetext{
7 Para o ano 2000 não se conseguiu identificar a participação apenas do setor de serviço excluindose o da administração pública. Portanto, pode-se ter subestimado a participação da agropecuária para os outros municípios, retirando-se os serviços vinculados à administração pública na composição do PIB municipal.
} 
a agropecuária se sobressaiu como principal atividade; em Mucuri a indústria é a mais relevante e nos demais municípios o setor de serviços. De forma geral, percebe-se transformação importante em pouco mais de uma década (2000 a 2014) na dinâmica econômica dos municípios, resultante da expansão da produção de eucalipto nos municípios estudados.

Tabela 3- Participação percentual das atividades econômicas no PIB dos municípios pesquisados, Bahia, anos 2000 e 2014.

\begin{tabular}{|c|c|c|c|c|c|c|c|c|c|c|}
\hline \multirow{3}{*}{ MUNICÍPIOS } & \multicolumn{10}{|c|}{ Participação Percentual das Atividades Econômicas no PIB-M } \\
\hline & \multicolumn{2}{|c|}{$\begin{array}{c}\text { Agropecuária } \\
(\%)\end{array}$} & \multicolumn{2}{|c|}{$\begin{array}{c}\text { Indústria } \\
(\%)\end{array}$} & \multicolumn{2}{|c|}{$\begin{array}{l}\text { Serviços } \\
\text { (\%) }\end{array}$} & \multicolumn{2}{|c|}{$\begin{array}{c}\text { Impostos } \\
(\%)\end{array}$} & \multicolumn{2}{|c|}{$\begin{array}{c}\text { Administração } \\
\text { Pública (\%) }\end{array}$} \\
\hline & 2000 & 2014 & 2000 & 2014 & 2000 & 2014 & 2000 & 2014 & 2000 & 2014 \\
\hline Alcobaça & 49,0 & 27,2 & 5,9 & 4,7 & 42,6 & 31,1 & 2,5 & 4,1 & - & 32,9 \\
\hline Belmonte & 28,7 & 27,7 & 10,3 & 6,1 & 57,9 & 30,6 & 3,1 & 4,0 & - & 31,6 \\
\hline Caravelas & 56,5 & 37,8 & 4,3 & 4,4 & 36,4 & 29,8 & 2,8 & 5,1 & - & 22,9 \\
\hline Mascote & 19,0 & 28,4 & 11,2 & 4,8 & 66,9 & 25,0 & 2,9 & 4,1 & - & 37,7 \\
\hline Mucuri & 11,6 & 3,9 & 49,6 & 54,6 & 27,6 & 21,7 & 11,2 & 9,2 & - & 10,6 \\
\hline Nova Viçosa & 31,1 & 9,0 & 9,9 & 8,1 & 51,6 & 43,8 & 7,5 & 10,2 & - & 28,9 \\
\hline Porto Seguro & 7,2 & 2,8 & 13,3 & 8,3 & 69,9 & 60,9 & 9,6 & 7,4 & - & 20,6 \\
\hline Santa Cruz Cabrália & 24,6 & 13,0 & 15,8 & 7,8 & 55,1 & 42,7 & 4,6 & 5,9 & - & 30,6 \\
\hline Teixeira de Freitas & 7,8 & 3,7 & 13,9 & 11,7 & 66,4 & 54,5 & 11,9 & 11,1 & - & 19,0 \\
\hline
\end{tabular}

Por sua vez, no ano de 2015, retirando-se a participação da administração pública, o setor de serviços predominou nos municípios de Alcobaça, Nova Viçosa, Porto Seguro, Santa Cruz Cabrália e Teixeira de Freitas; já nos municípios de Belmonte, Caravelas e Mascote, predominou o setor agropecuário; e no município de Mucuri predominou o setor industrial. No ano de 2017, à exceção do município de Mucuri no qual continuou predominando o setor industrial, e em Mascote onde predominava a agropecuária quase em igualdade com o setor de serviços, em todos os outros sete municípios já predominava o setor de serviços (Tabela 4).

Tabela 4- Participação percentual das atividades econômicas no PIB dos municípios pesquisados, Bahia, anos 2015 e 2017.

\begin{tabular}{|c|c|c|c|c|c|c|c|c|c|c|}
\hline \multirow{3}{*}{ MUNICÍPIOS } & \multicolumn{10}{|c|}{ Participação Percentual das Atividades Econômicas no PIB-M } \\
\hline & \multicolumn{2}{|c|}{$\begin{array}{c}\text { Agropecuária } \\
(\%)\end{array}$} & \multicolumn{2}{|c|}{$\begin{array}{l}\text { Indústria } \\
\text { (\%) }\end{array}$} & \multicolumn{2}{|c|}{$\begin{array}{c}\text { Serviços } \\
(\%)\end{array}$} & \multicolumn{2}{|c|}{$\begin{array}{c}\text { Impostos } \\
(\%)\end{array}$} & \multicolumn{2}{|c|}{$\begin{array}{l}\text { Administração } \\
\text { Pública (\%) }\end{array}$} \\
\hline & 2015 & 2017 & 2015 & 2017 & 2015 & 2017 & 2015 & 2017 & 2015 & 2017 \\
\hline Alcobaça & 26,4 & 28,6 & 4,5 & 5,0 & 32,4 & 31,4 & 4,7 & 5,0 & 32,0 & 30,0 \\
\hline Belmonte & 31,5 & 22,9 & 6,6 & 5,8 & 30,3 & 33,9 & 4,0 & 4,8 & 27,6 & 32,6 \\
\hline Caravelas & 38,2 & 29,3 & 6,6 & 7,9 & 29,5 & 32,7 & 5,1 & 6,0 & 20,6 & 24,1 \\
\hline Mascote & 28,0 & 28,3 & 5,1 & 4,4 & 26,0 & 28,1 & 4,5 & 5,2 & 36,4 & 34,0 \\
\hline Mucuri & 3,0 & 3,4 & 61,0 & 57,0 & 20,0 & 21,4 & 8,0 & 9,0 & 8,0 & 9,2 \\
\hline Nova Viçosa & 9,4 & 9,0 & 10,0 & 9,0 & 42,0 & 42,0 & 9,6 & 10,0 & 29,0 & 30,0 \\
\hline Porto Seguro & 2,6 & 3,4 & 8,0 & 7,3 & 60,4 & 62,3 & 8,0 & 7,5 & 21,0 & 19,5 \\
\hline Santa Cruz Cabrália & 10,0 & 17,3 & 8,0 & 9,0 & 45,0 & 42,0 & 6,0 & 5,4 & 31,0 & 26,3 \\
\hline Teixeira de Freitas & 4,5 & 3,6 & 10,1 & 8,4 & 54,5 & 55,0 & 10,4 & 11,0 & 20,5 & 22,0 \\
\hline
\end{tabular}


Espacialmente a produção de madeira em tora para papel e celulose além de potencializar a economia dos municípios, evidenciado pelo crescimento do PIB de serviços e indústria, gerou efeitos positivos sobre o PIB per capita e outros indicadores. No período entre os anos 2000, 2010, 2012, 2014 e 2017, houve incremento no PIB per capita para todos os municípios considerados (Tabela 5). No entanto, a despeito disso, as transformações sociais seriam geradas se esse incremento fosse efetivamente apropriado igualitariamente pela população local, porém isso não ocorreu, pois o índice Gini ${ }^{8}$ Renda (Tabela 6) mostra concentração, revelando que apenas parte da população se apropriou dos incrementos no PIB.

Esse fato permite inferir que, embora tendo importância econômica para os municípios, a produção de eucalipto não implicou em transformações sociais relevantes do ponto de vista de significativa melhoria nas condições de vida da maior parcela da população desses municípios, pois os maiores beneficiados são alguns poucos segmentos desses locais.

Tabela 5- Produto Interno Bruto per capita (PIB per capita), em reais, dos municípios pesquisados, Bahia, anos 2000, 2010, 2012, 2014 e 2017.

\begin{tabular}{l|c|c|c|c|c}
\hline \multirow{2}{*}{ Município } & \multicolumn{5}{c}{ PIB per capita dos municípios (R\$)/ Ano } \\
\cline { 2 - 6 } & $\mathbf{2 0 0 0}$ & $\mathbf{2 0 1 0}$ & $\mathbf{2 0 1 2}$ & $\mathbf{2 0 1 4}$ & $\mathbf{2 0 1 7}$ \\
\hline Alcobaça & $3.135,30$ & $8.437,05$ & $9.070,39$ & $9.017,65$ & $11.298,81$ \\
Belmonte & $1.704,65$ & $7.580,74$ & $9.446,28$ & $9.735,56$ & $11.055,40$ \\
Caravelas & $4.271,18$ & $12.272,49$ & $13.117,80$ & $12.743,28$ & $14.165,63$ \\
Mascote & $1.099,23$ & $4.952,12$ & $6.296,82$ & $7.718,77$ & $10.171,68$ \\
Mucuri & $14.573,80$ & $35.104,23$ & $32.107,56$ & $33.503,76$ & $46.974,21$ \\
Nova Viçosa & $2.516,85$ & $7.105,61$ & $8.190,69$ & $9.337,52$ & $10.903,17$ \\
Porto Seguro & $2.453,36$ & $9.306,49$ & $11.507,28$ & $14.502,12$ & $18.888,98$ \\
Santa Cruz Cabrália & $1.967,01$ & $6.562,37$ & $7.999,37$ & $9.839,71$ & $13.818,49$ \\
Teixeira de Freitas & $2.626,71$ & $9.418,22$ & $10.573,45$ & $12.460,61$ & $14.298,26$ \\
\hline
\end{tabular}

Fonte: IBGE/DATASUS. Disponível em: <http://www.deepask.com/goes?page=alcobaca/BA-Confirao-PIB---Produto-Interno-Bruto---no-seu-municipio> Acesso em: 05/08/2019.

Nota-se, ainda, por meio da Tabela 6, que, no transcorrer do tempo, poucos municípios conseguiram reduzir a desigualdade na distribuição de renda, e que essa redução foi pouco expressiva.

\footnotetext{
8 O Índice de Gini renda varia entre 0 e 1, quanto mais próximo de 0 menos concentrada é a renda, quanto mais próximo de 1 , mais concentrada é a renda.
} 
Tabela 6- Índice de Gini renda dos nove municípios produtores de eucalipto considerados, Bahia, Brasil, em 1991, 2000 e 2010.

\begin{tabular}{lrrrrr}
\hline & \multicolumn{2}{c}{ Coeficiente de Gini renda } & \multicolumn{2}{c}{ Variação (\%) } \\
\hline Município & 1991 & 2000 & 2010 & $1991 / 2000$ & $2000 / 2010$ \\
\hline Alcobaça & 0,5802 & 0,5539 & 0,5345 & $-4,53 \%$ & $-3,50 \%$ \\
Belmonte & 0,5407 & 0,5909 & 0,4979 & $9,28 \%$ & $-15,74 \%$ \\
Caravelas & 0,5195 & 0,7355 & 0,5873 & $41,58 \%$ & $-20,15 \%$ \\
Mascote & 0,5772 & 0,5473 & 0,6026 & $-5,18 \%$ & $10,10 \%$ \\
Mucuri & 0,5397 & 0,6141 & 0,5969 & $13,79 \%$ & $-2,80 \%$ \\
Nova Viçosa & 0,5324 & 0,6173 & 0,6230 & $15,95 \%$ & $0,92 \%$ \\
Porto Seguro & 0,6613 & 0,6342 & 0,5693 & $-4,10 \%$ & $-10,23 \%$ \\
Santa Cruz Cabrália & 0,6223 & 0,6442 & 0,5875 & $3,52 \%$ & $-8,80 \%$ \\
Teixeira de Freitas & 0,6186 & 0,6311 & 0,5408 & $2,02 \%$ & $-14,31 \%$ \\
\hline Fonte: IBGE; SEl-BA (2015) & & & & &
\end{tabular}

Outro indicador relevante para captar transformações sociais é o IDH-M cujos valores dos municípios em análise encontram-se dispostos na Tabela 7. Os dados apresentados na citada tabela sinalizam gradativa melhora nas condições dos municípios considerados na análise.

Em 1991 todos os nove municípios se encontravam na condição de desenvolvimento muito baixo, semelhante à média da Bahia, sendo longevidade a variável com melhor desempenho; em seguida a renda; e educação a variável com pior desempenho. No ano 2000 todos os municípios, à exceção de Mucuri que passou para condição de "baixo desenvolvimento", continuavam na condição de muito baixo desenvolvimento. E novamente, a educação apresentava o pior desempenho entre as variáveis componentes do IDH. Já em 2010, sete municípios haviam elevado a sua condição para "médio desenvolvimento", seguindo a tendência do estado, exceto os municípios de Belmonte e Mascote que se encontravam na condição de baixo desenvolvimento. Esse crescimento dos valores do IDH-M e de seus componentes pode ter sido influenciado por diferentes programas sociais nas esferas federal e estadual de governo, os quais favoreceram diretamente a população menos favorecida, sobretudo a partir do ano 2000.

\footnotetext{
${ }^{9} \mathrm{O}$ Índice de Desenvolvimento Humano dos municípios (IDH-M) considera no seu cálculo indicadores de Educação, Longevidade e Renda. O seu valor varia entre 0 e 1 . Quanto mais próximo de 0 menor é o grau de desenvolvimento do município e quanto mais próximo de 1 , maior o grau de desenvolvimento. Entre 0 a 0,499 "desenvolvimento muito baixo"; 0,500 a 0,599 "desenvolvimento baixo"; 0,600 a 0,699 "desenvolvimento médio"; 0,700 a 0,799 "desenvolvimento alto"; e 0,800 a 1 "desenvolvimento muito alto" (PNUD, 2015).
} 
Tabela 7- Índice de Desenvolvimento Humano Municipal dos municípios, em 1991, 2000 e 2010, e estado da Bahia.

\begin{tabular}{|c|c|c|c|c|c|c|c|c|c|c|c|c|}
\hline \multirow[b]{2}{*}{ Município } & \multicolumn{3}{|c|}{$\begin{array}{l}\text { IDHM } \\
\text { Total }\end{array}$} & \multicolumn{3}{|c|}{$\begin{array}{c}\text { IDHM } \\
\text { Educação }\end{array}$} & \multicolumn{3}{|c|}{$\begin{array}{c}\text { IDHM } \\
\text { Longevidade }\end{array}$} & \multicolumn{3}{|c|}{$\begin{array}{l}\text { IDHM } \\
\text { Renda }\end{array}$} \\
\hline & 1991 & 2000 & 2 & 91 & 2000 & 20 & 1991 & 2000 & 2010 & 1991 & 2000 & 2010 \\
\hline Nov & 18 & 455 & 0 & 2 & 0 , & 6 & 48 & 0,646 & 0,780 & 25 & 0,556 & 0 \\
\hline Cara & 271 & 0,473 & 0,616 & 077 & 0,258 & 0,473 & 0,555 & 0,663 & 0,791 & 0,467 & 0,619 & 0,6 \\
\hline IVI & 75 & 0,525 & 0,665 & 072 & 0,351 & 0,541 & 0,555 & 0,679 & 0,801 & 0,522 & 0,607 & 0,679 \\
\hline & 272 & 0,453 & 0,608 & 078 & 0,271 & 0,476 & 0,563 & 0,631 & 0,771 & 0,459 & 0,543 & 0,6 \\
\hline Port & 0,367 & 0,495 & 0,676 & 0,145 & 0,277 & 0,572 & 0,627 & 0,702 & 0,801 & 0,544 & 0,625 & 0,673 \\
\hline San & 0,334 & 0,486 & 0,654 & 0,119 & 0,273 & 0,571 & 0,625 & 0,692 & 0,784 & 0,502 & 0,607 & 0,624 \\
\hline & & 0,356 & 0,5 & 039 & 0,159 & 0,464 & & 0,610 & 0,744 & 0,402 & 0,464 & 0,5 \\
\hline Tei> & 0,378 & 0,539 & 0,685 & 0,169 & 0,366 & 0,588 & 0,558 & 0,679 & 0,800 & 0,571 & 0,629 & 0,683 \\
\hline Belr & 0,310 & 0,441 & 0,598 & 0,123 & 0,249 & 0,480 & 0,524 & 0,638 & 0,771 & 0,464 & 0,541 & 0,577 \\
\hline Média & 0,317 & 0,484 & 0,644 & 0,113 & 0,289 & 0,529 & 0,578 & 0,665 & 0,786 & 0,503 & 0,591 & 0,642 \\
\hline Furicu & 0,386 & 0,512 & 0,660 & 0,182 & 0,332 & 0,55 & 0,582 & 0,680 & 0,783 & 0,543 & 0,594 & 0,663 \\
\hline
\end{tabular}

Fonte: Atlas do Desenvolvimento Humano no Brasil (2015).

Ao analisar a realidade social por meio do indicador "Índice de Vulnerabilidade Social (IVS)", verifica-se que no ano 2000 os nove municípios apresentavam significativa vulnerabilidade social (Tabela 8), a qual se reduziu em 2010, corroborando assim os resultados do IDH-M (ver tabela 7). Dentre as quatro dimensões consideradas, capital humano, renda e trabalho se posicionam como de maior vulnerabilidade, exceção para a infraestrutura urbana.

Tabela 8- Índice de Vulnerabilidade Social para os municípios pesquisados para os anos 2000 e 2010, Bahia.

\begin{tabular}{lll}
\hline Municípios & $\mathbf{2 0 0 0}$ & $\mathbf{2 0 1 0}$ \\
\hline Alcobaça & 0,596 & 0,480 \\
Belmonte & 0,717 & 0,517 \\
Caravelas & 0,717 & 0,530 \\
Mucuri & 0,511 & 0,415 \\
Nova Viçosa & 0,663 & 0,496 \\
Porto Seguro & 0,540 & 0,341 \\
Mascote & 0,747 & 0,569 \\
Teixeira de Freitas & 0,513 & 0,362 \\
Santa Cruz Cabrália & 0,552 & 0,422 \\
\hline Média & 0,610 & 0,450 \\
\hline Bahia & 0,552 & 0,403 \\
\hline Brasil & 0,446 & 0,362 \\
\hline Fon:
\end{tabular}

Fonte: IPEA - Atlas da Vulnerabilidade Social (2015). 
Os reflexos da expansão da silvicultura e da pecuária nos municípios podem ser observados no aumento de grandes propriedades de terras - conforme se observa a expansão dessas atividades, por exemplo, entre os anos 2000 e 2010, por meio da figura 2. Essa substituição na forma de uso da terra potencializou o processo de migração rural-urbana, efetivando nos municípios estudados a urbanização, a qual já vinha em curso no Brasil desde a década de 1960.

Figura 2- Evolução da população rural e do uso do solo rural com silvicultura, pastagem com manejo e áreas agrícolas, nos municípios, Bahia, em 2000 e 2010.

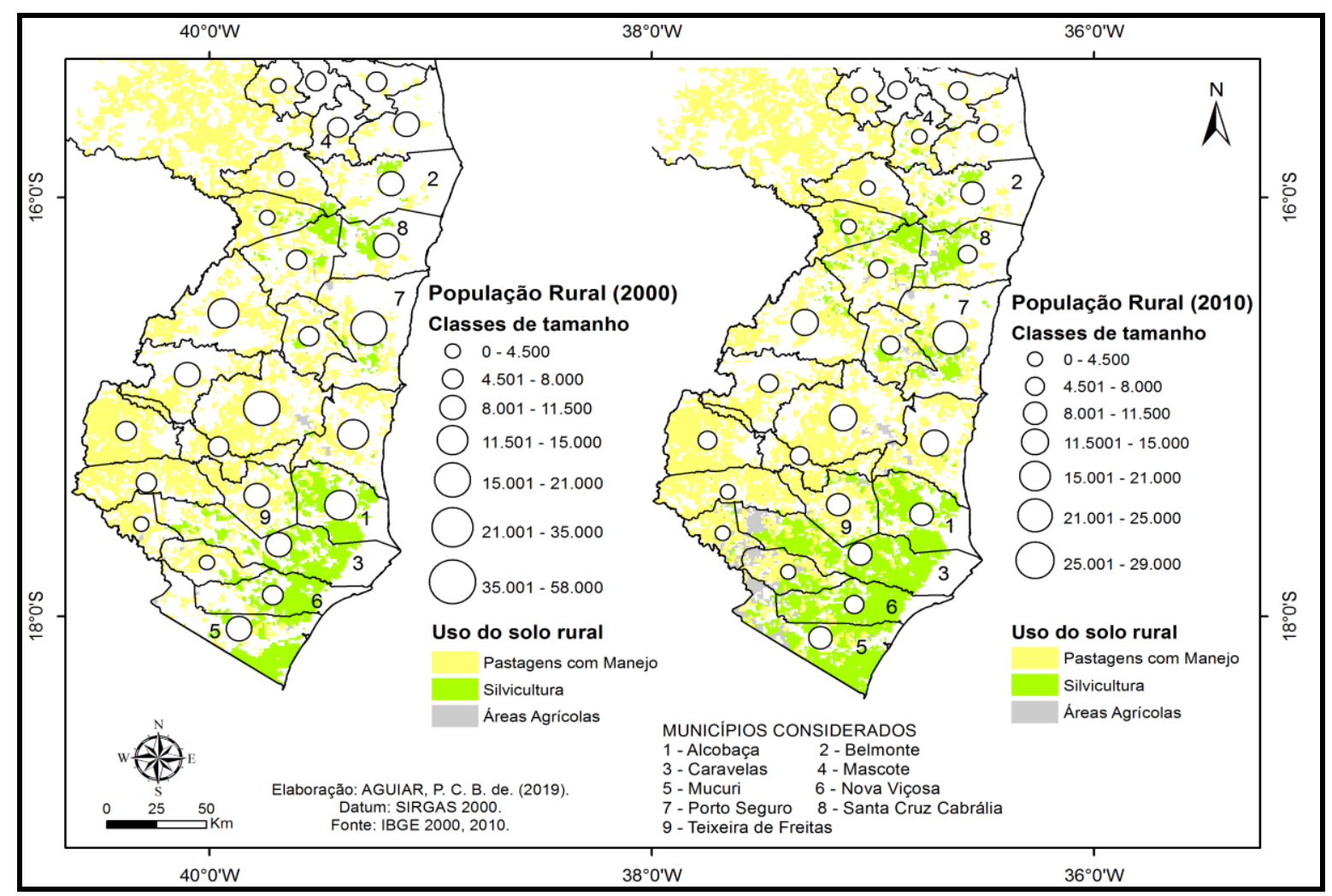

Elaboração própria: Paulo César B. de Aguiar, a partir de IBGE (2000; 2010).

Conforme se pode observar por meio da tabela 9, no ano de 1991 os municípios eram predominantemente rurais; uma década depois (2000), apenas no município de Alcobaça nota-se uma população rural superior à urbana; e em 2010, a maior parcela da população dos nove municípios vivia nas cidades. Isso revela que o processo de urbanização se consolida a medida que se expandem os plantios de eucalipto (ver Tabela 1), o qual se torna cada vez mais tecnificados, e, consequentemente, "poupadores" de mão de obra, levando a um novo "desenho" sociodemográfico da região, com alteração no mosaico da paisagem rural. 
Tabela 9- População rural, urbana e total dos municípios analisados, Bahia, em 1991, 2000 e 2010.

\begin{tabular}{l|cc|c|c|c|c|c|c|c}
\hline \multirow{2}{*}{ Município } & \multicolumn{3}{|c|}{$\mathbf{1 9 9 1}$} & \multicolumn{3}{c|}{$\mathbf{2 0 0 0}$} & \multicolumn{3}{c}{$\mathbf{2 0 1 0}$} \\
\cline { 2 - 10 } & Rural & Urbana & Total & Rural & Urbana & Total & Rural & Urbana & Total \\
\hline Alcobaça & 10.224 & 5.464 & 15.688 & 13.520 & 7.446 & 20.966 & 10.186 & 11.085 & 21.271 \\
Belmonte & 10.718 & 10.860 & 21.578 & 9.003 & 10.806 & 19.809 & 10.378 & 11.420 & 21.798 \\
Caravelas & 10.603 & 8.932 & 19.535 & 9.771 & 10.332 & 20.103 & 10.105 & 11.309 & 21.414 \\
Mascote & 20.277 & 1.573 & 21.850 & 5.696 & 11.853 & 17.549 & 2.961 & 11.679 & 14.640 \\
Mucuri & 12.796 & 4.810 & 17.606 & 9.377 & 18.685 & 28.062 & 8.534 & 27.492 & 36.026 \\
Nova Viçosa & 16.196 & 9.374 & 25.570 & 7.440 & 24.636 & 32.076 & 5.030 & 33.526 & 38.556 \\
Porto Seguro & 11.216 & 23.315 & 34.531 & 15.911 & 79.619 & 95.530 & 22.851 & 104.078 & 126.929 \\
S.C.Cabrália & 3.338 & 3.197 & 6.535 & 10.361 & 13.527 & 23.888 & 7.262 & 19.002 & 26.264 \\
T. de Freitas & 11.326 & 74.221 & 85.547 & 8.798 & 98.688 & 107.486 & 9.078 & 129.263 & 138.341 \\
\hline
\end{tabular}

Fonte: PNUD. Atlas de Desenvolvimento Humano no Brasil (2013).

Dados do último Censo Agropecuário do IBGE (2017) apontam que, dentre os nove municípios, Caravelas, Mucuri e Nova Viçosa, respectivamente, foram os que destinaram maior parcela de área para a produção de eucalipto. Em termos de valor da produção, os maiores foram, respectivamente, em Santa Cruz Cabrália, Caravelas e Mucuri (Gráfico 4). Por outro lado, os menores valores da produção de madeira em tora, foram nos municípios de Mascote, Teixeira de Freitas e Porto Seguro. Os dois últimos municípios são polos regionais e passaram por intenso processo de urbanização, sendo Teixeira de Freitas um polo regional no setor de serviços e Porto Seguro um polo turístico de destaque nacional e internacional.

Gráfico 4- Área total (ha) destinada à produção de eucalipto e valor da produção de madeira em tora nos nove municípios, Bahia, 2017.

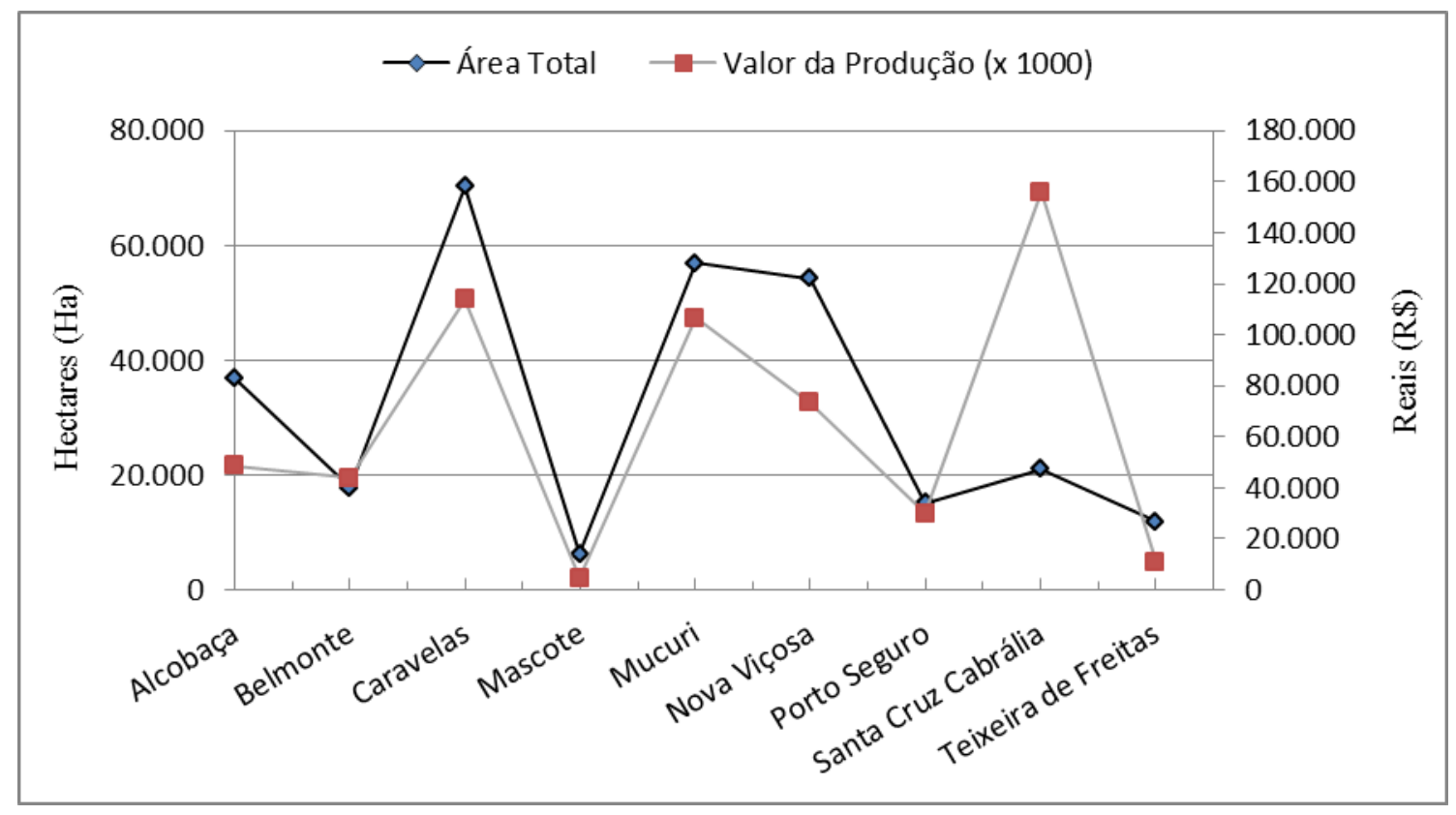

Fonte: IBGE - Censo Agropecuário (2017). 
Ao se comparar o número e a área dos estabelecimentos agropecuários dos anos censitários 2006 e 2017 (Tabela 10), percebe-se que em 2006 os municípios que possuíam o maior número de estabelecimentos agropecuários foram, respectivamente, Alcobaça, Belmonte e Mucuri; já as maiores áreas totais dos estabelecimentos estavam nos municípios de Porto Seguro, Mucuri e Caravelas.

Tabela 10- Estabelecimentos agropecuários dos municípios analisados, Bahia, em 2006 e 2017.

\begin{tabular}{l|c|c|c|c|c}
\hline \multirow{2}{*}{ Municípios } & $\begin{array}{c}\text { Território } \\
\text { Municipal }\end{array}$ & & \multicolumn{2}{c|}{ Estabelecimentos (em 2006) } & \multicolumn{2}{c}{ Estabelecimentos (em 2017) } \\
\cline { 5 - 6 } & Quantid. & $\begin{array}{c}\text { Área Total (x1000) } \\
\text { ha }\end{array}$ & Quantid. & $\begin{array}{c}\text { Área Total (x 1000) } \\
\text { ha }\end{array}$ \\
\hline Alcobaça & $1.482,285 \mathrm{~km}^{2}$ & 1.194 & 31.375 & 1.246 & 51.427 \\
Belmonte & $1.939,447 \mathrm{~km}^{2}$ & 1.189 & 117.807 & 1.397 & 104.961 \\
Caravelas & $2.377,872 \mathrm{~km}^{2}$ & 764 & 119.368 & 1.005 & 143.133 \\
Mascote & $742,689 \mathrm{~km}^{2}$ & 544 & 49.926 & 569 & 46.339 \\
Mucuri & $1.787,626 \mathrm{~km}^{2}$ & 986 & 126.078 & 987 & 194.435 \\
Nova Viçosa & $1.316,380 \mathrm{~km}^{2}$ & 558 & 71.986 & 552 & 146.989 \\
Porto Seguro & $2.285,764 \mathrm{~km}^{2}$ & 853 & 139.196 & 1.538 & 135.056 \\
Santa Cruz Cabrália & $1.462,942 \mathrm{~km}^{2}$ & 861 & 112.622 & 883 & 51.278 \\
Teixeira de Freitas & $1.165,622 \mathrm{~km}^{2}$ & 741 & 88.376 & 967 & 100.114 \\
\hline
\end{tabular}

Fonte: IBGE - Censos Agropecuários (2006 e 2017).

Por sua vez, no ano de 2017 os municípios com maior número de estabelecimentos agropecuários foram Porto Seguro, Belmonte e Alcobaça; já as maiores áreas totais dos estabelecimentos agropecuários estavam nos municípios de Mucuri, Nova Viçosa e Caravelas. À exceção do município de Nova Viçosa, todos os demais apresentaram aumento no número de estabelecimentos agropecuários entre 2006 e 2017. Em relação à área não se observou um padrão definido.

\section{Considerações Finais}

O estudo realizado evidenciou transformações relevantes na silvicultura baiana, passando de uma situação de inexpressividade para ocupar a segunda posição no ranking nacional de maiores produtores de madeira em tora para produção de papel e celulose no ano de 2014. Tal posicionamento deveu-se à expansão da produção nos nove municípios que compuseram as análises aqui expostas, pois esses foram responsáveis por quase $70 \%$ da produção do estado da Bahia. Embora, em anos recentes, o estado tenha declinado da segunda posição.

Para se atingir o patamar de produção de eucalipto, muitas também foram as transformações observadas em nível local, que vão desde a dinâmica econômica até organização socioespacial dos municípios. O eucalipto tornou-se a principal fonte de geração de renda de alguns municípios, levando-os a um rápido e tardio processo 
de urbanização. Ademais, a estrutura produtiva se altera, passando de municípios predominantemente agrícolas para fornecedores de produtos industrializados e de serviços, muito embora, substancialmente vinculados à produção de eucalipto.

Se a atividade potencializou a economia, os indicadores sociais revelam que o crescimento econômico não foi "experimentado" pela maior parte da população, haja vista os indicadores, apesar da melhora, revelar concentração de renda, vulnerabilidade social e fraco desenvolvimento.

Além disso, a expansão dos plantios de eucalipto tem gerado uma transformação na paisagem rural, em razão da maior concentração de terras pelo aumento no número de grandes propriedades rurais, o que leva à "expulsão" de pequenos produtores do espaço rural para o urbano, consolidando o processo de urbanização observado nesses municípios.

De forma geral, nota-se que há necessidade de políticas públicas que reduzam a concentração de renda e terra, de forma que os avanços econômicos gerados com a introdução da eucaliptocultura possam ser apropriados por um maior número de pessoas componentes da população desses municípios produtores, sobretudo dos segmentos menos favorecidos.

\section{REFERÊNCIAS}

ABAF. Associação Baiana das Empresas de Base Florestal, Bahia Florestal, ano base 2012. Anuário ABAF: 2013.

ANTONANGELO, A.; BACHA, C. J. C. As Fases da Silvicultura no Brasil. Revista Brasileira de Economia, Rio de Janeiro, 52 (1): 207-238 Jan./Mar. 1998. Disponível em:

http://bibliotecadigital.fgv.br/ojs/index.php/rbe/article/view/721/8086. Acesso em: 10 set. 2019.

Associação Brasileira de Celulose e Papel (BRACELPA). Conjuntura BRACELPA. BRACELPA, jan. 2014. Mensal. Disponível em:

http://bracelpa.org.br/bra2/sites/default/files/conjuntura/CB-062.pdf. Acesso em: 13 mai. 2014.

BACHA, C. J. C. A dinâmica do desmatamento e do reflorestamento no Brasil. Piracicaba, Esalq/USP. (Tese de Livre Docência), 1993.

BIAZUS, A.; HORA, A. B. da.; LEITE, B. G. P. Papel e Celulose: o potencial de investimento nos setores florestal, de celulose e papel. In: TORRES, E.; PUGA, F.; MEIRELLES, F. B.

Perspectivas do Investimento: 2010-2013. Rio de Janeiro: BNDES, 2011.

Câmara Setorial de Silvicultura. Agenda Estratégica do Setor de Florestas Plantadas, 2009. Disponível em:

http://www.agricultura.gov.br/arq_editor/file/camaras_setoriais/Florestas_plantadas/9reuniao/ Agenda_Sivicultura.pdf. Acesso em: 22 jun. 2015. 
CARRIELLO, F.; VICENS, R. S. Silvicultura de eucalipto no vale do Paraíba do Sul/SP no período entre 1986 e 2010. In: Simpósio Brasileiro de Sensoriamento Remoto, 15.

(SBRS), 2011, Curitiba. Anais... São José dos Campos: INPE. p. 6403-6409. Disponível em: http://marte.sid.inpe.br/col/dpi.inpe.br/marte/2011/07.14.17.57/doc/p0974.pdf. Acesso em: 10 set. 2014.

CERQUEIRA Neto, S. P. G. Três décadas de Eucalipto no Extremo Sul da Bahia. GEOUSP - Espaço e Tempo, São Paulo. Vol. 31, 2012, p. 55-68. Disponível em:

http://www.revistas.usp.br/geousp/article/view/74252. Acesso em: 10 set. 2015.

Companhia de Tecnologia de Saneamento Ambiental - CETESB. Guia técnico ambiental da indústria de papel e celulose - Série I. São Paulo: CETESB, 2008. 49 p.

Federação das Indústrias do Estado da Bahia - FIEB. Comércio Exterior: Bahia e Brasil, Março, 2014. Disponível em:

http://www.fieb.org.br/Adm/FCKimagens/file/SDI/2014/Comercio\%20Exterior\%20marco\%201 4.pdf. Acesso em: 12 set.2015.

HENDERSON, J. M.; QUANDT, R. R. Teoria microeconômica: uma abordagem matemática. 2 ed. São Paulo: Pioneira, 1988. 417p.

Instituto Brasileiro de Geografia e Estatística - IBGE. Cidades. Disponível em: http://cod.ibge.gov.br/8WO. Acesso em: 11 jun. 2015.

Instituto Brasileiro de Geografia e Estatística - IBGE. Cidades. Disponível em: http://cod.ibge.gov.br/1E3. Acesso em: 11 jun. 2015.

Instituto Brasileiro de Geografia e Estatística - IBGE. Cidades. Disponível em: http://cod.ibge.gov.br/GRP. Acesso em: 18 jul. 2019.

Instituto Brasileiro de Geografia e Estatística - IBGE. Cidades. Censo Agropecuário Municipal, 2017. Disponível em:

https://cidades.ibge.gov.br/brasil/ba/alcobaca/pesquisa/24/76693. Acesso em: 10 set. 2019.

Instituto Brasileiro de Geografia e Estatística - IBGE. Sistema IBGE de Recuperação Automática - SIDRA. Disponível em:

http://www.sidra.ibge.gov.br/bda/tabela/protabl.asp?c=1613\&z=t\&o=11\&i=P. Acesso em: 18 jul. 2019.

INVESTEXPORT BRASIL. Guia de Comércio Exterior e Investimento. Como exportar: Finlândia. 2014. Disponível em:

http://www.investexportbrasil.gov.br/sites/default/files/publicacoes/comoExportar/CEXFinlandi a.pdf. Acesso em: 20 set. 2015.

MARTINI, A. J. O Plantador de Eucaliptos: A questão da preservação ambiental no Brasil e o resgate documental do legado de Edmundo Navarro de Andrade. 332f. Tese. Doutorado em História Social: Universidade de São Paulo, 2004. Disponível em:

http://www.ipef.br/servicos/teses/arquivos/martini,aj.pdf. Acesso em: 11 jun. 2015.

MDIC. Ministério da Indústria, Comércio Exterior e Serviços. Estatísticas do Comércio Exterior de Serviços - 2015. Disponível em: http://www.mdic.gov.br/comercioservicos/estatisticas-do-comercio-exterior-de-servicos/717-estatisticas-do-comercio-exteriorde-servicos-2015. Acesso em: 10 set. 2019.

PUITुEL, A. C. et al. Sustainable use of recovered paper in the Romanian Paper Industry. Part II - Environmental Impact. Environmental engineering and Management Journal, Cluj, v. 13, n. 8, 2014, p. 1909-1915, August. Disponível em: 
http://omicron.ch.tuiasi.ro/EEMJ/pdfs/vol13/no8/Full/8_167_Puitel_14.pdf. Acesso em: 17 jul. 2015.

Secretaria da Indústria, Comércio e Mineração (SICM), 2014. Disponível em:

http://www.sde.ba.gov.br/Pagina.aspx?pagina=papelecelulose. Acesso em: 9 jun. de 2014.

SILVA, L. F. de., MENDONÇA, J. R. Terras Avistadas por Cabral (Mata Atlântica): 500 anos de devastação. Ilhéus, BA: Editus, 2000.

VIANA, M. B. O eucalipto e os efeitos ambientais do seu plantio em escala. Biblioteca Digital da Câmara dos Deputados. Brasília, 2004.

XAVIER, A.; SILVA, R. L. da. Evolução da Silvicultura clonal de Eucalyptus no Brasil. Agronomia Costarricense, vol. 34. 2010, p. 93-98. Disponível em: http://www.mag.go.cr/rev_agr/v34n01_093.pdf. Acesso em: 23 dez 2015.

\section{NOTAS DE AUTOR}

\section{CONTRIBUIÇÃO DE AUTORIA}

Mônica de Moura Pires - Concepção. Análise de dados, Elaboração do manuscrito, revisão e aprovação da versão final do trabalho.

Paulo César Bahia de Aguiar - Levantamento de dados secundários, Análise de dados, Elaboração de mapas e gráficos, revisão e aprovação da versão final do trabalho.

Érika Giulia Fragas Santana - Concepção e elaboração do manuscrito. Coleta de dados, Análise dos dados, Elaboração de tabelas e gráficos. Participação ativa da discussão dos resultados; Revisão e aprovação da versão final do trabalho.

\section{FINANCIAMENTO}

Bolsa da Coordenação de Aperfeiçoamento de Pessoal de Nível Superior - CAPES.

\section{CONSENTIMENTO DE USO DE IMAGEM}

Não se aplica

APROVAÇÃO DE COMITÊ DE ÉTICA EM PESQUISA

Não se aplica

\section{CONFLITO DE INTERESSES}

Não se aplica

\section{LICENÇA DE USO}

Este artigo está licenciado sob a Licença Creative Commons CC-BY. Com essa licença você pode compartilhar, adaptar, criar para qualquer fim, desde que atribua a autoria da obra.

\section{HISTÓRICO}

Recebido em: 14-10-2019

Aprovado em: 06-05-2020 